\title{
Factors that Influence the Terminal Grading of Sands
}

\section{P.M.V.Ferreira ${ }^{+}$and M.R.Coop ${ }^{+}$}

+ University College London

Corresponding Author:

Dr Pedro Miguel Vaz Ferreira - e-mail: p.ferreira@ucl.ac.uk

Department of Civil, Environmental and Geomatic Engineering

University College London

Gower Street

London WC1E 6BT

Phone: +44 2076794366

Professor Matthew coop - e-mail: m.coop@ucl.ac.uk 


\title{
Nomenclature
}

$\mathrm{B}_{\mathrm{r}} \quad$ relative breakage (Hardin, 1985)

d fractal dimension

DBS Dogs Bay sand

DG decomposed granite

$\mathrm{H}_{0} \quad$ initial sample height

$\delta_{s} \quad$ shear displacement

$\gamma \quad$ shear strain

$\varphi^{\prime} \quad$ angle of shearing resistance

$\sigma^{\prime}{ }_{\mathrm{v}} \quad$ vertical stress

\begin{abstract}
Coop et al. (2004) found that for a carbonate sand shearing to extremely large strains allowed the soil to reach a stable grading; findings also reported by others for a limited range of sands, typically sedimentary and often weak grained. This paper describes similar tests on a soil of very different geological origin, a weathered soil, that confirms similar patterns of behaviour. Tests investigating factors affecting the final grading for both soils indicated small effects of shearing velocity but significant effects of the initial grading, highlighting that the final fractal dimension is not a constant.
\end{abstract}

Keywords: Terminal Grading, Shearing, Granular soil. (Fractals, Sands, Shear strenght) 


\section{Introduction}

The existence of a final grading has become a central assumption in the mechanics of coarse grained soils. In compression, McDowell \& Bolton (1998) found that breakage caused the gradings to tend towards a fractal, plotting as a straight line on a log:log particle size distribution with a fractal dimension $d$ of around 2.5. Coop et al. (2004) then investigated final gradings in a ring shear apparatus, finding a final fractal distribution with a slightly higher $\mathrm{d}$ of 2.57 that also corresponded to a cessation of volumetric compression. Einav (2007a, b) and Muir Wood (2008) moved to quantifying breakage, based on a final fractal grading, within their constitutive models.

Ultimate fractal distributions seemed to be supported by natural gradings of some less common soils that have undergone intense shearing in-situ, notably sub-glacial tills, debris flow materials and fault gouges (Sammis et al., 1987; Hooke and Iverson, 1995) and Altuhafi et al. (2011) found that a fractal glacial till did not undergo further breakage during either compression or shear. However, in each case the fractal dimensions were not constant. Further doubts about the immutability of the final grading arise from the observation that, in Coop et al. (2004), the final stable grading was different at each stress level, so it is not known what would have been achieved had the capacity of the apparatus permitted tests at larger stresses. They also only tested a uniform grading of one particularly weak grained carbonate sand, although in a different type of ring shear Sadrekarimi and Olson (2014) had reached terminal gradings for three sands with stronger grains. Their final gradings also depended on stress level, while the locus of the voids ratios at these terminal states plotted well below the critical state line from triaxial tests.

Other doubts about the fundamental nature of the ultimate grading arose from work on gap graded soils where in both compression and shear the knee in the grading prevented a simple fractal 
developing (Zhang and Baudet, 2013; Miao and Airey, 2013; Zhang et al., 2017). Miao and Airey also identified that even for simpler gradings, original features were retained in the final grading.

This paper draws together unpublished data from tests using the same techniques as Coop et al. (2004) but which illustrate other factors that may influence the final particle breakage.

\section{Apparatus and Experimental Procedures}

The tests were carried out in a Bishop ring shear (Bishop et al. 1971), with 203mm OD, 152mm ID and $23 \mathrm{~mm}$ sample height, modified for fast shearing so that new tests at $190 \mathrm{~mm} / \mathrm{min}$ could be compared with previous ones at $1.9 \mathrm{~mm} / \mathrm{min}$. The principal advantages of this apparatus are that the shearing is at the mid-height and the loss in vertical stress due to friction on the side walls may be measured, by lifting the upper ring and measuring the downwards force. This is done in stages as the gap between the rings causes soil losses, limiting the strains that may be reached. As the sample height reduces so do the friction losses, so that even if the vertical stress is known accurately, which it is not in some ring shear designs, the changing friction means it is quite variable. For each test, a range of net vertical stresses is therefore given in Table 1 and tests must be compared in which the vertical stresses are not exactly the same, which is not ideal.

Tests were carried out on two sands; the Dog's Bay biogenic carbonate sand, DBS, used by Coop et al. (2004) and a Korean decomposed granite, DG (Lee and Coop, 1995). The DG is of Grade V (Geological Society, 1990) with a mineralogy dominated by quartz and feldspar, with smaller quantities of mica, smectite and kaolin. The DBS was tested from a variety of initial gradings while one grading of the decomposed granite was used, which is given in Fig.1. This grading is close to a fractal dimension of 2.65 applied over the size limits $0.3-2 \mathrm{~mm}$; Miao and Airey (2013) had tested a carbonate sand with an initial fractal grading limited between bounds 
defined by the grading (the effects of applying bounds to fractal distributions are discussed below).

The tests on the DBS were carried out at the same nominal stresses used by Coop et al., 100, 400 and $1000 \mathrm{kPa}$, while for the DG, only $400 \mathrm{kPa}$ was used.

The more uniformly graded samples were created by pluviation through water and wet compaction was used for the better graded samples, typically in five layers, with gentle tamping to create the desired density, although in most cases the samples were made in loose states. The advantage of using a ring shear over a triaxial apparatus is that the very much larger strains permit the particle breakage to stabilise, while the strains imposed in a triaxial test are far from sufficient to reach such a state. However, the disadvantage is the much less uniform strains within the sample. Loose samples minimise the effects of strain localisation although Luzzani and Coop (2002) showed that even so there is localisation of strains around a central zone of about $5 \mathrm{~mm}$ thickness. After each test, the soil from this central zone was collected and wet sieved; sedimentation was used in some cases to establish the fines distribution.

\section{The Evolution of Grading in Decomposed Granite}

The evolution of the grading curves for the DG is shown in Fig. 1. Shear strain $\gamma$ was calculated as:

$$
\gamma=\frac{\delta_{s}}{H_{0}}
$$

where $\delta_{\mathrm{s}}$ is the shear displacement and $\mathrm{H}_{0}$ the initial height; because of localisation, this is only a nominal strain.

There is an evolution towards a unique final grading for strains of $17400 \%$ and above, with only minor changes after the test at $6910 \%$. In the $\log : \log$ plot, the fractal terminal grading $\mathrm{d}=2.57$, determined by Coop et al. (2004) for the DBS at 1MPa nominal is indicated. However, the shape 
of the final grading is more complex and cannot be perfectly fitted by a single fractal as Miao and Airey (2013) highlighted and as Coop et al. found for the tests on DBS at stress levels of 100 and $400 \mathrm{kPa}$. Miao and Airey also determined lower fractal dimensions for the fines which were not measured here.

For consistency with the previous work, the particle breakage has been quantified with $\mathrm{B}_{\mathrm{r}}$, defined by Hardin (1985) as the ratio of the area between the initial and final gradings curves to the area above the initial curve, however the cut-off used here is of $63 \mu \mathrm{m}$, rather than the $74 \mu \mathrm{m}$ originally proposed. This is clearly not an ideal means of quantifying breakage as it ignores any contribution to breakage below the cut-off. However, it allows the breakage to be quantified by a single number and avoids any assumption about a terminal grading, the uniqueness of which is challenged by the data presented in this paper.

The $\mathrm{B}_{\mathrm{r}}$ data for the DG sheared at the slow speed is shown on Fig.2, along with the data of Coop et al. (2004) for DBS. The asymptotes at zero strain for the 1MPa tests on DBS and the new tests on DG are provided by oedometer tests. The DG reaches a final value of $\mathrm{B}_{\mathrm{r}}$, indicating the cessation of breakage, at a strain of about 5000-6000\%, similar to the DBS tests at similar stress levels but different $B_{r}$ values partly because of the different initial grading. Most previous work on terminal gradings has been on weak bioclastic carbonate sands (e.g. Coop et al., 2004; Miao and Airey, 2013), clastic sedimentary soils and basaltic glacial sediments (Sadrekarimi and Olson, 2014; Zhang et al., 2017) and these data confirm that similar behaviour is seen in a soil with a weathered rock origin, despite the rather different breakage processes that these soils undergo. Lee \& Coop (1995) had shown that the DG is composed of aggregated particles of different minerals, the clay minerals being attached to the non-clay minerals and Madhusudhan \& Baudet (2014) found that the clay minerals would only become detached and act as separate particles under 
vigorous washing. Zhao et al. (2015) investigated in detail the breakage mechanisms of a similar DG, finding that the mode of breakage was rather dissimilar to other sands, being by means of separation of particles along mineral boundaries, splitting along the cleavage of minerals that had one, and fractures along pre-existing flaws such as micro-fissures. It is interesting that even with such different forms of breakage, the patterns of grading evolution in the DG are still similar to the DBS.

\section{Mobilised Strength of the Decomposed Granite}

Coop et al. (2004) found that for the DBS the mobilised angle of shearing resistance, $\varphi^{\prime}$, remained constant at all stress levels and for all shear strains. Similar data are shown for the DG in Fig.3, for the gap-open stages, when the stresses are accurately measured. The mobilised $\varphi^{\prime}$ could only be defined at small strains for the slow tests, where the denser sample DG7 has a peak strength. At larger strains, the data confirm that the mobilised $\varphi^{\prime}$ is insensitive to the intense breakage. The mobilised strength could be affected by both the grading and the distribution of particle shapes, although the shapes were not measured here. While Altuhafi \& Coop (2011) found a small decrease of sphericity in their ring shear tests on a quartz sand, Miao \& Airey (2013) found an increase of aspect ratio for their tests on a carbonate sand. Differences in evolution of shape for different sands might explain why no change of mobilised $\varphi^{\prime}$ was seen either in these DG tests or those on DBS by Coop et al. (2004) while Sadrekarimi \& Olson (2010) saw a small increase of $\varphi^{\prime}$ that they believed corresponded to an increase of angularity in three predominantly quartz sands.

\section{The Influence of Speed of Shearing}


Most of the tests on the DG were carried out at the faster velocity of $190 \mathrm{~mm} / \mathrm{min}$, but three were at $1.9 \mathrm{~mm} / \mathrm{min}$. On Fig. 1, the gradings for slow shearing plot slightly higher than those of the fast, and this is confirmed in Fig.4(a) in terms of slightly higher Br. The mobilised $\varphi^{\prime}$ on Fig.3 are insensitive to the shear rate. It was not possible to shear fast at a nominal stress of $1 \mathrm{MPa}$, and so tests were carried out on the DBS at the two lower stresses. Figure 4(b) again only shows a small effect of velocity, and at both stress levels there is a lower breakage at low strains for fast shearing but a slightly higher final breakage. Miao and Airey (2013) concluded that speed did not make a difference to the breakage, but their fast and slow tests were carried out in two very different apparatus, while here, in otherwise identical tests it is clear that there are effects, although small and not consistent between different soil types.

\section{The Influence of Initial Grading Curve}

The final fractal of 2.57 given in Coop et al. (2004) was based on the final state of poorly graded DBS. These data are replotted in Fig.5(a) for test RS3 along with the fractal dimension of 2.57. The comminution limit is around $1 \mu \mathrm{m}$ for many rock minerals and this was confirmed for a soil by Vilhar et al. (2013). Miao and Airey (2013) followed Einav (2007a) in adapting the fractal distribution to accommodate the comminution limit, imposing a minimum particle size $\mathrm{D}_{\min }$ within the grading, using Equation 2:

[2] $\quad \%$ passing $=\frac{D^{(3-d)}-D_{\min }^{(3-d)}}{D_{\max }^{(3-d)}-D_{\min }^{(3-d)}}$

where $\mathrm{D}$ is the particle size. If this is used, then by trial and error the best fit fractal dimension $\mathrm{d}$ for RS3 becomes 2.68. The imposition of a comminution limit means that the fractal particle size 
distribution must break down as that limit is approached, since on a log : log particle size distribution the curve cannot be straight, self-similarity must cease, and the curve must dive towards minus infinity. At larger particle sizes however, there is only a small influence of the limit so the curves using $\mathrm{d}=2.68$ in Equation 2 or 2.57 without the limit are close. For clarity the distribution given by Equation 2 is referred to within this paper as a "limited fractal". In fact, even if a comminution limit should be expected, none of the distributions on Fig.5(a) could be represented by Equation 2 and a limiting size at $1 \mu \mathrm{m}$, as used by Miao and Airey (2013) because the "limited fractal" grading plunges asymptotically towards that limit below about $0.02 \mathrm{~mm}$. This discrepancy may be the result either of deficiencies of the sedimentation method or a resolution issue of the Morphologi system of Miao and Airey. However, even at larger particle sizes above $0.02 \mathrm{~mm}$, it is the straight true fractal with $\mathrm{d}=2.57$ that fits RS3 better than the slight curvature still caused at that size by Equation 2 .

Interestingly, RS5 which was similar to RS3, at a nominal stress of $1 \mathrm{MPa}$, but which through the vagaries of the friction correction had a slightly higher net stress also had a slightly higher grading. More significantly, a better graded sample, RS8, gave a noticeably higher grading curve, again a true fractal, but with a dimension of 2.67 assuming no comminution limit. Two more tests were carried out to examine the effects of initial grading. DBS19 started with the same initial grading as the mean final grading of RS3 and RS5. In contrast to the findings of Altuhafi et al. (2010), additional breakage did occur, although the final grading was similar to that of RS8. DBS18 was created at a grading higher than the final ones of RS3 and RS5, and breakage still occurred, resulting in a final grading of $\mathrm{d}=2.79$, again fitted using a true fractal and assuming no limit (although the fractal is curved here because of the use of a linear \% passing scale on Fig.5(b)). 
Figure 6 shows an investigation of the effect of the absolute size of the initial grading. As Coop et al. (2004) had indicated, test RS7, with a finer grading, shows an almost parallel shift in the final grading compared to RS3 and RS5, although the fractal dimension (not shown on the figure) is slightly higher at 2.62. Most of the tests were carried out on loose samples, but DBS1-5 were on slightly denser samples. There seems to be an effect of initial density on the final grading, for example comparing DBS2 with RS7, which were sheared to similar strains. However, the comparison is slightly compromised by the higher friction in the dense samples, meaning that the vertical stress was lower and tests in a better controlled ring shear would be needed to confirm this. It is clear though that as the initial grading becomes coarser, the final grading does change shape from concave to convex in the top of the curve, when a linear scale is used.

\section{Conclusions}

Ring shear tests on a weathered soil have confirmed similar patterns of grading evolution to those seen by Coop et al. (2004) and others on carbonate sands and other sedimentary sands. The final grading could be approximated as a fractal with dimension 2.57 as for the DBS, even if the tests were at a lower stress level, but details of the grading departed from this. Changing the rate of shearing over two orders of magnitude only had a small effect on the breakage and with inconsistent effects between the two soils. There was no significant effect of shearing speed on the mobilised angle of shearing resistance, which also seemed insensitive to the continuing breakage. Tests on the DBS at different gradings and densities again confirmed that there was nothing fixed about a final fractal grading of dimension 2.57 , and that the final grading was sensitive to the initial grading and possibly the sample density, with well graded samples reaching final gradings of significantly higher fractal dimensions. The lack of a final stable grading that applies even for one 
soil, calls into question the definition of breakage used by Einav (2007a, b) and Muir Wood (2008) and may mean that, with all of its defects, a simpler definition like that of Hardin (1985) may be more appropriate.

\section{Acknowledgements}

The authors would like to thank the following for their contributions to the test programme: Ms.E.Andropolou, Mr.C.W.Loo, Mr.G.I.Chryssovitsiotis and Mr.W.W.Cheung.

\section{References}

Altuhafi, F., Baudet, B. A. \& Sammonds, P. (2011) On the particle size distribution of a basaltic till. Soils and Founds. 51(1): 113-121.

Altuhafi, F. \& Coop, M.R. (2011) The Effect of Mode of Loading on Particle-scale Damage. Soils \& Foundations 51(5), 849-856.

Bishop, A.W., Green, G.E., Garga, V.K., Andresen, A. and Brown, J.D. (1971) A new ring shear apparatus and its application to the measurement of residual strength. Géotechnique, 21(4):

Coop, M.R., Sorensen, K.K., Bodas Freitas, T. and Georgoutsos, G. (2004) Particle breakage during shearing of a carbonate sand, Géotechnique, 54(3): 157-163.

Einav, I. (2007a) Breakage mechanics_-Part I: theory. Journal of the Mechanics and Physics of Solids, 55(6): 1274-1297.

Einav, I. (2007b) Breakage mechanics-Part II: modelling granular materials. Journal of the Mechanics and Physics of Solids, 55(6): 1298-1320.

Geological Society (1990) Tropical Residual Soils: Working Party Report. Quart. J. Eng. Geol., 23(1), 1-101. 
Hardin, B.O. (1985) Crushing of soil particles. Journal of Geotechnical Engineering - ASCE, 111(10): 1177-1192.

Hooke, R.LeB. and Iverson, N.R. (1995) Grain size distribution in deforming subglacial tills: role of grain fracture. Geology 57-60.

Kendall, K. (1978) The impossibility of comminuting small particles by compression. Nature, 272, $710-711$.

Lee, I.K. and Coop, M.R. (1995) The Intrinsic Behaviour of Decomposed Granite Soil. Géotechnique, 45(1): 117-130.

Luzzani, L. and Coop, M.R. (2002) On the relationship between particle breakage and the critical state of sands. Soils and Foundations, 42(2): 71-82.

Madhusudhan, B. N. and Baudet, B. A. (2014) Influence of reconstitution method on the behaviour of completely decomposed granite. Géotechnique, 64(7): 540-550.

McDowell, G.R. and Bolton, M.D. (1998) On the micromechanics of crushable aggregates. Géotechnique, 48(5): 667-679.

Miao, G. and Airey, D. (2013) Breakage and ultimate states for a carbonate sand. Géotechnique 63(14): 1221-1229.

Muir Wood, D. (2008) Critical states and soil modelling. In Proceedings of the fourth International Symposium on Deformational Characteristics of Geomaterials, Atlanta, Georgia, 21-24 September 2008, IOS Press/Millpress, Amsterdam, Vol. 1, pp. 51-72.

Sadrekarimi, A. and Olson, S.M. (2010) Particle damage observed in ring shear tests on sands. Can. Geoech. J., 47, 497-515.

Sadrekarimi, A. and Olson, S.M. (2014) Residual State of Sands. J. Geotech. Geoenviron. Eng., 140(4): 04013045 
Sammis, C., King, G. \& Biegel, R. (1987) The kinematics of gouge deformation. Pure Appl. Geophys. 125(5): 777-812.

Vilhar, G., Jovicic, V. \& Coop, M.R. (2013) The role of particle breakage in the mechanics of a non-plastic silty sand. Soils and Foundations, 53(1): 91-104.

Zhang, X. and Baudet, B.A. (2013) Particle breakage in gap-graded soil. Géotechnique Letters, 3(2): 72-77.

Zhang, X., Baudet, B.A., Hu, W. and Xu, Q. (2017) Characterisation of the ultimate particle size distribution of uniform and gap-graded soils. Soils and Foundations 57: 603-618.

Zhao, B., Wang, J., Coop, M.R., Viggiani, G. \& Jiang, M. (2015) An Investigation of Single Sand Particle Fracture Using X-Ray Micro-tomography. Géotechnique 65(8), 625-641. 
Table 1 Summary of tests conducted (Tests LC1-4 are DBS tests from Luzzani \& Coop, 2002; Tests RS1-15 are DBS tests from Coop et al., 2004).

\begin{tabular}{|c|c|c|c|c|c|c|}
\hline Test & Notes & $\begin{array}{c}\text { Initial grading } \\
(\mu \mathrm{m})\end{array}$ & $\begin{array}{l}\mathrm{v} \text { prior to } \\
\text { shearing }\end{array}$ & $\begin{array}{c}\text { Nominal / Net } \\
\sigma^{\prime}{ }_{v}(\mathrm{kPa})\end{array}$ & $\begin{array}{c}\text { Speed } \\
(\mathrm{mm} / \mathrm{min}) \\
\end{array}$ & Final $\gamma(\%)$ \\
\hline LC1 & & $300-425$ & 2.58 & $1000 / \approx 805$ & 1.9 & 207 \\
\hline LC2 & & $300-425$ & 2.61 & $1000 / \approx 805$ & 1.9 & 730 \\
\hline LC3 & & $300-425$ & 2.57 & $1000 / \approx 805$ & 1.9 & 104 \\
\hline LC4 & & $300-425$ & 2.56 & $1000 / \approx 805$ & 1.9 & 251 \\
\hline RS1 & & $300-425$ & 2.51 & $1000 / \approx 670$ & 1.9 & 171 \\
\hline RS2 & & $300-425$ & 2.46 & $1000 / \approx 670$ & 1.9 & 2860 \\
\hline RS3 & & $300-425$ & 2.55 & $1000 / 650-660$ & 1.9 & 11100 \\
\hline RS4 & & $300-425$ & 2.52 & $1000 / \approx 670$ & 1.9 & 1430 \\
\hline RS5 & & $300-425$ & 2.46 & $1000 / 740-860$ & 1.9 & 11030 \\
\hline RS6 & & $300-425$ & 2.43 & $1000 / 750-820$ & 1.9 & 2780 \\
\hline RS7 & Finer grading & $212-300$ & 2.41 & $1000 / 750-850$ & 1.9 & 2910 \\
\hline RS8 & Well graded & $63-425$ & 1.96 & $1000 / 725-825$ & 1.9 & 11710 \\
\hline RS9 & & $300-425$ & 2.50 & $400 / 250-280$ & 1.9 & 10920 \\
\hline RS10 & & $300-425$ & 2.47 & $400 / 248-346$ & 1.9 & 3350 \\
\hline RS11 & & $300-425$ & 2.46 & $400 / 283-375$ & 1.9 & 13280 \\
\hline RS12 & & $300-425$ & 2.45 & $400 / 296-368$ & 1.9 & 1180 \\
\hline RS13 & & $300-425$ & 2.59 & $400 / 288-386$ & 1.9 & 26650 \\
\hline RS14 & & $300-425$ & 2.60 & $400 / 290-343$ & 1.9 & 285 \\
\hline RS15 & & $300-425$ & 2.50 & $100 / 60-77$ & 1.9 & 147000 \\
\hline RS16 & & $300-425$ & 2.79 & $100 / 62-70$ & 1.9 & 9040 \\
\hline RS17 & & $300-425$ & 2.72 & $100 / 66-80$ & 1.9 & 31700 \\
\hline RS18 & & $300-425$ & 2.68 & $100 / 78-94$ & 1.9 & 23900 \\
\hline RS19 & & $300-425$ & 2.69 & $100 / 68-97$ & 1.9 & 37500 \\
\hline DBS1 & $\begin{array}{l}\text { Denser, finer } \\
\text { grading }\end{array}$ & $150-212$ & 1.91 & $1000 / 550-700$ & 2.1 & 3688 \\
\hline DBS2 & $\begin{array}{l}\text { Denser, finer } \\
\text { grading }\end{array}$ & $212-300$ & 2.64 & $1000 / 550-750$ & 2.1 & 3826 \\
\hline DBS3 & Denser & $300-425$ & 2.34 & $1000 / 625-680$ & 2.1 & 3616 \\
\hline DBS4 & $\begin{array}{l}\text { Denser, } \\
\text { coarser grading }\end{array}$ & $425-600$ & 2.40 & $1000 / 530-560$ & 2.1 & 3111 \\
\hline DBS5 & $\begin{array}{l}\text { Denser, } \\
\text { coarser grading }\end{array}$ & $600-1180$ & 2.18 & $1000 / 650-730$ & 2.1 & 3103 \\
\hline DBS6 & & $300-425$ & 2.51 & 400 / 330-378 & 190 & 53146 \\
\hline DBS7 & & $300-425$ & 2.79 & $400 / 365-380$ & 190 & 2695 \\
\hline DBS8 & & $300-425$ & 2.32 & $400 / 330-380$ & 190 & 30030 \\
\hline DBS9 & & $300-425$ & $\mathrm{~N} / \mathrm{A}$ & $400 / 325-374$ & 190 & 472 \\
\hline DBS10 & & $300-425$ & 2.55 & $100 / 62-80$ & 190 & 50856 \\
\hline DBS11 & & $300-425$ & 2.10 & $100 / 60-90$ & 190 & 15016 \\
\hline DBS12 & & $300-425$ & 2.42 & $100 / 60-90$ & 190 & 12770 \\
\hline DBS13 & & $300-425$ & 2.13 & $100 / 60-90$ & 190 & 27011 \\
\hline DBS14 & & $300-425$ & 2.39 & $100 / 65-90$ & 190 & 53702 \\
\hline
\end{tabular}




\begin{tabular}{|l|l|c|c|c|c|r|}
\hline DBS15 & & $300-425$ & 2.77 & $100 / 53-61$ & 1.9 & 153321 \\
\hline DBS16 & & $300-425$ & 2.48 & $100 / 61-92$ & 190 & 113715 \\
\hline DBS17 & & $300-425$ & N/A & $100 / 80-88$ & 190 & 75151 \\
\hline DBS18 & Well graded & $<63-425$ & 2.26 & $1000 / 500-800$ & 2.1 & 3246 \\
\hline DBS19 & Well graded & $<63-425$ & 2.12 & $1000 / 500-800$ & 2.1 & 3539 \\
\hline DG1 & & $300-2000$ & 2.86 & $400 / 300-340$ & 190 & 34700 \\
\hline DG2 & & $300-2000$ & 2.93 & $400 / 320-330$ & 190 & 17400 \\
\hline DG3 & & $300-2000$ & 2.92 & $400 / 320-345$ & 190 & 6910 \\
\hline DG4 & & $300-2000$ & 2.94 & $400 / 330-345$ & 190 & 3450 \\
\hline DG5 & & $300-2000$ & 2.89 & $400 / 320-325$ & 190 & 37000 \\
\hline DG6 & Denser & $300-2000$ & 2.75 & $400 / 320-335$ & 190 & 46500 \\
\hline DG7 & Denser & $300-2000$ & 2.72 & $400 / 300-430$ & 1.9 & 44500 \\
\hline DG8 & & $300-2000$ & 2.90 & $400 / 300-310$ & 190 & 430 \\
\hline DG9 & & $300-2000$ & 2.92 & $400 / 290-335$ & 1.9 & 440 \\
\hline DG10 & & $300-2000$ & 2.89 & $400 / 290-335$ & 1.9 & 6940 \\
\hline
\end{tabular}




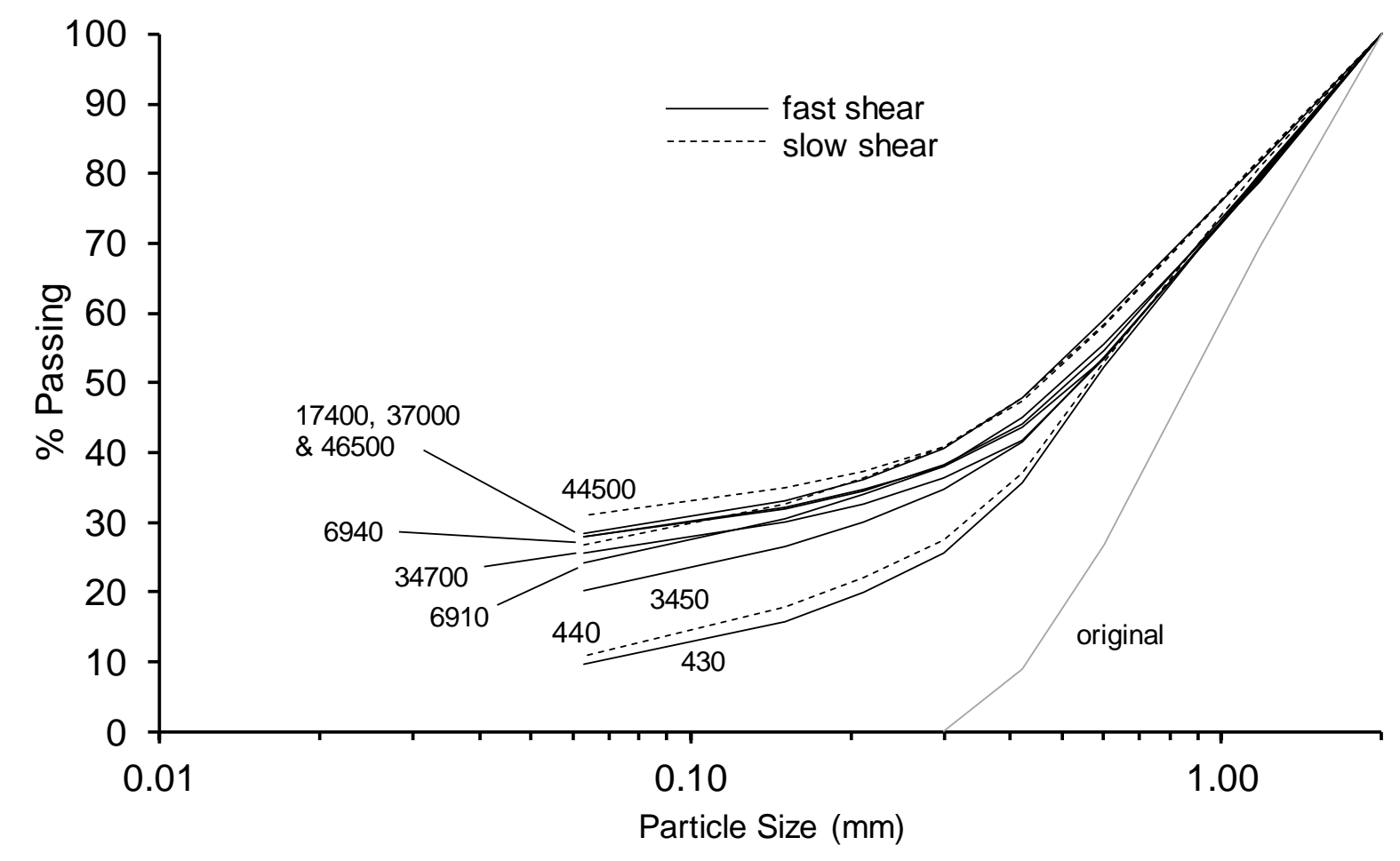

(a)

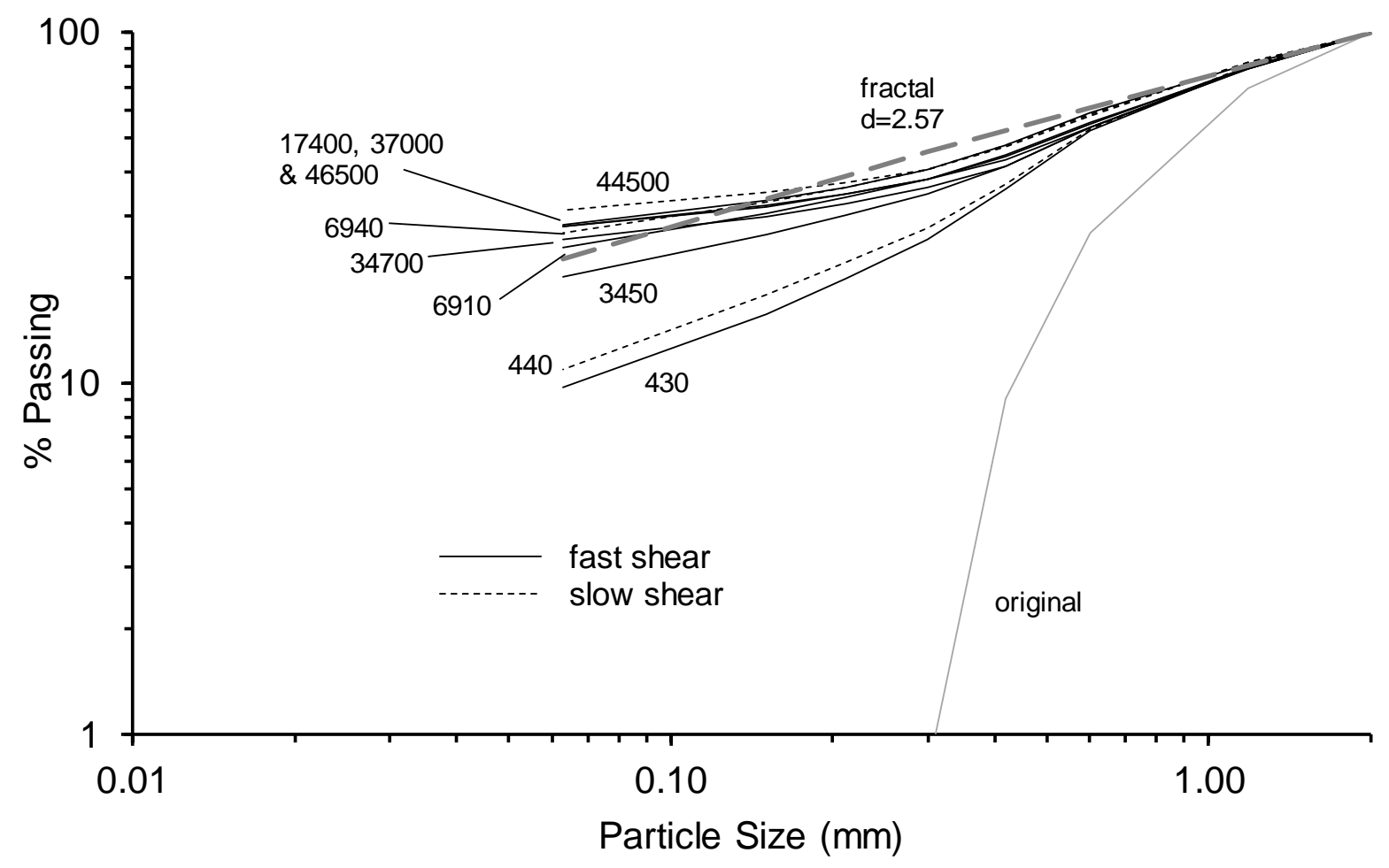

(b)

Fig.1 - Evolution of grading curves for decomposed granite with $\sigma^{\prime}{ }_{v}$ in range $290-430 \mathrm{kPa}$ (labels indicate final shear strain \%) 


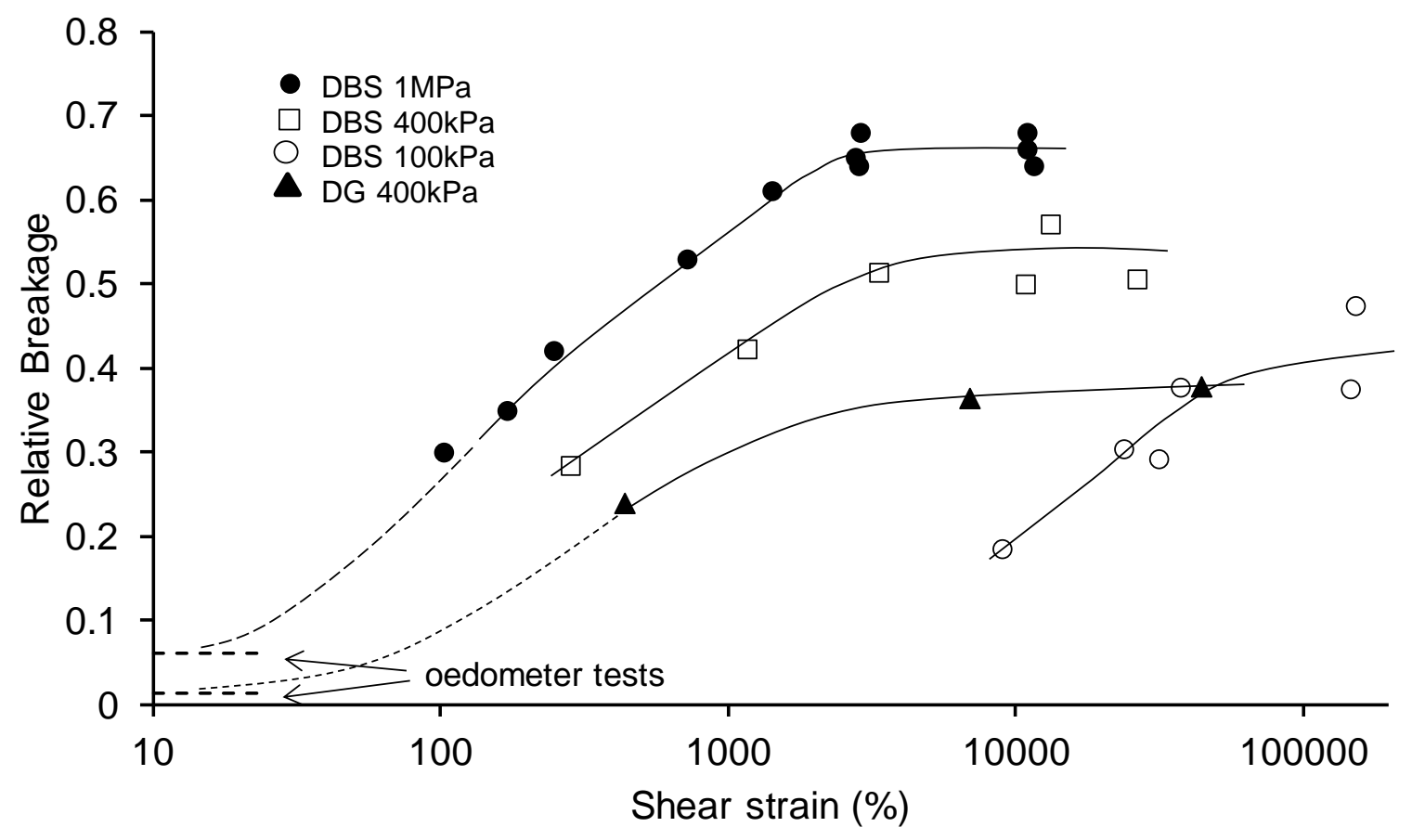

Fig.2 - Evolution of relative breakage for slow tests on decomposed granite (DG) at 400kPa and Dogs Bay sand at three stress levels (DBS data modified from Coop et al., 2004).

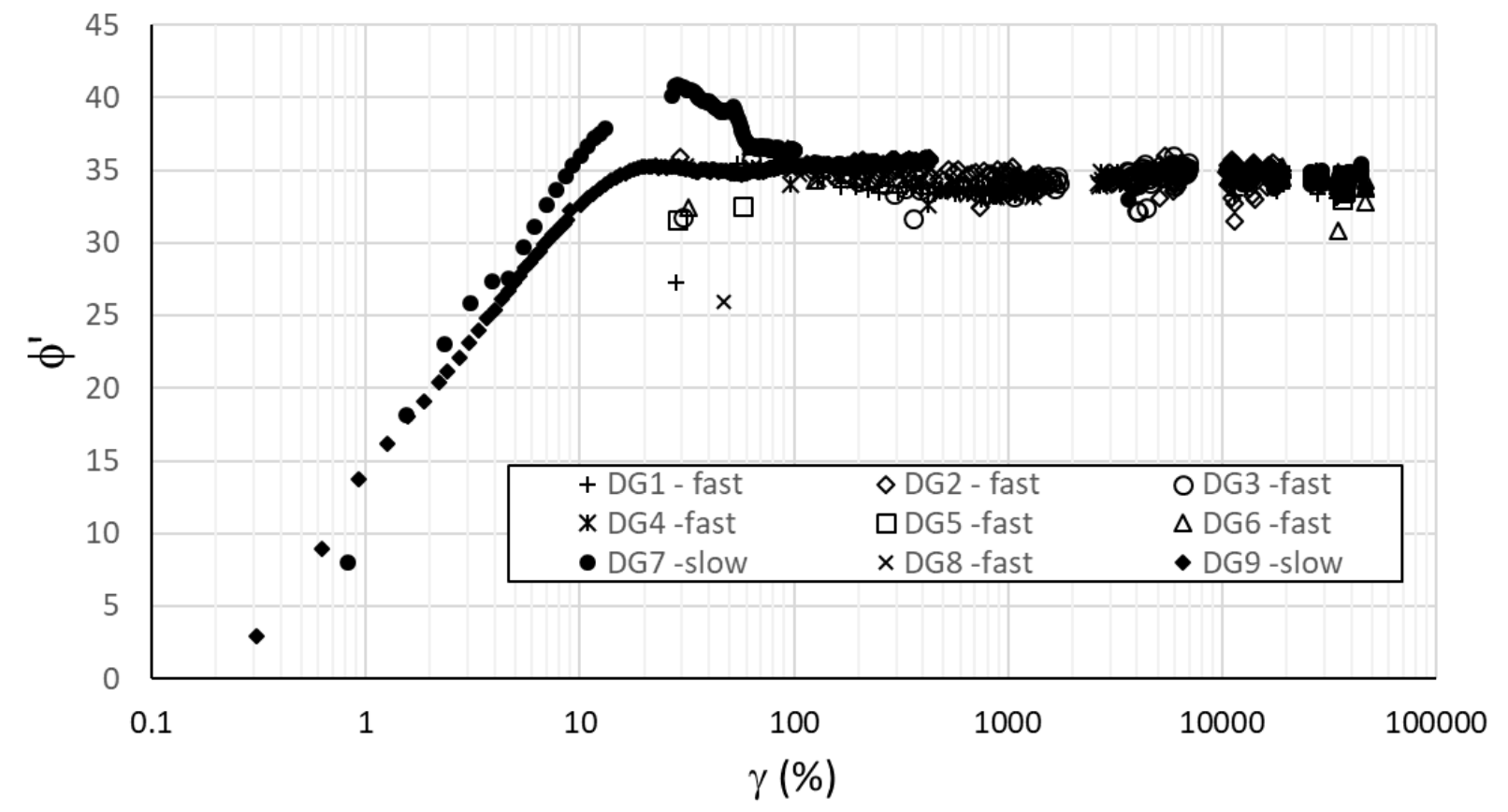

Fig.3 - Evolution of mobilised angle of shearing resistance with continued shearing. 


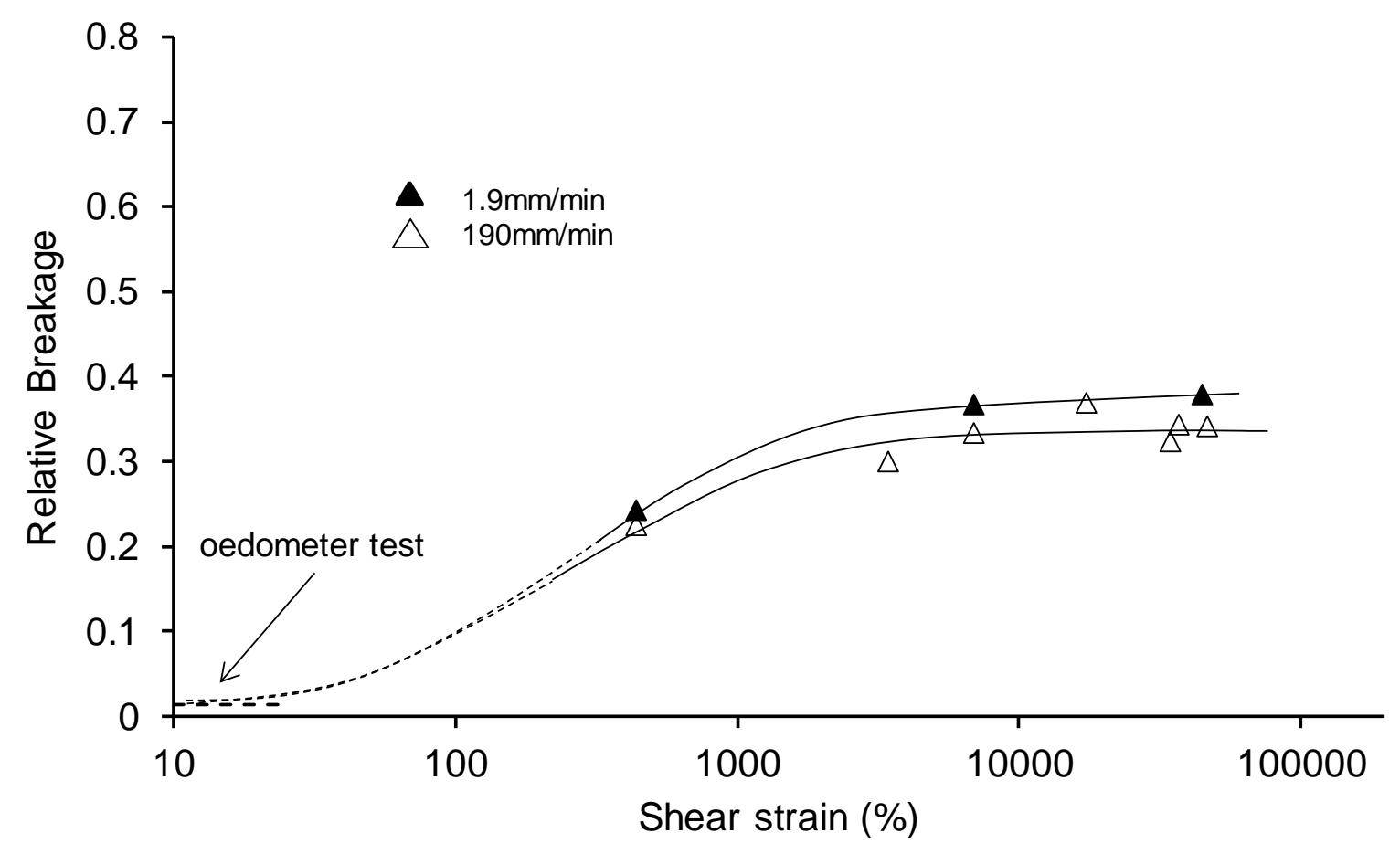

(a)

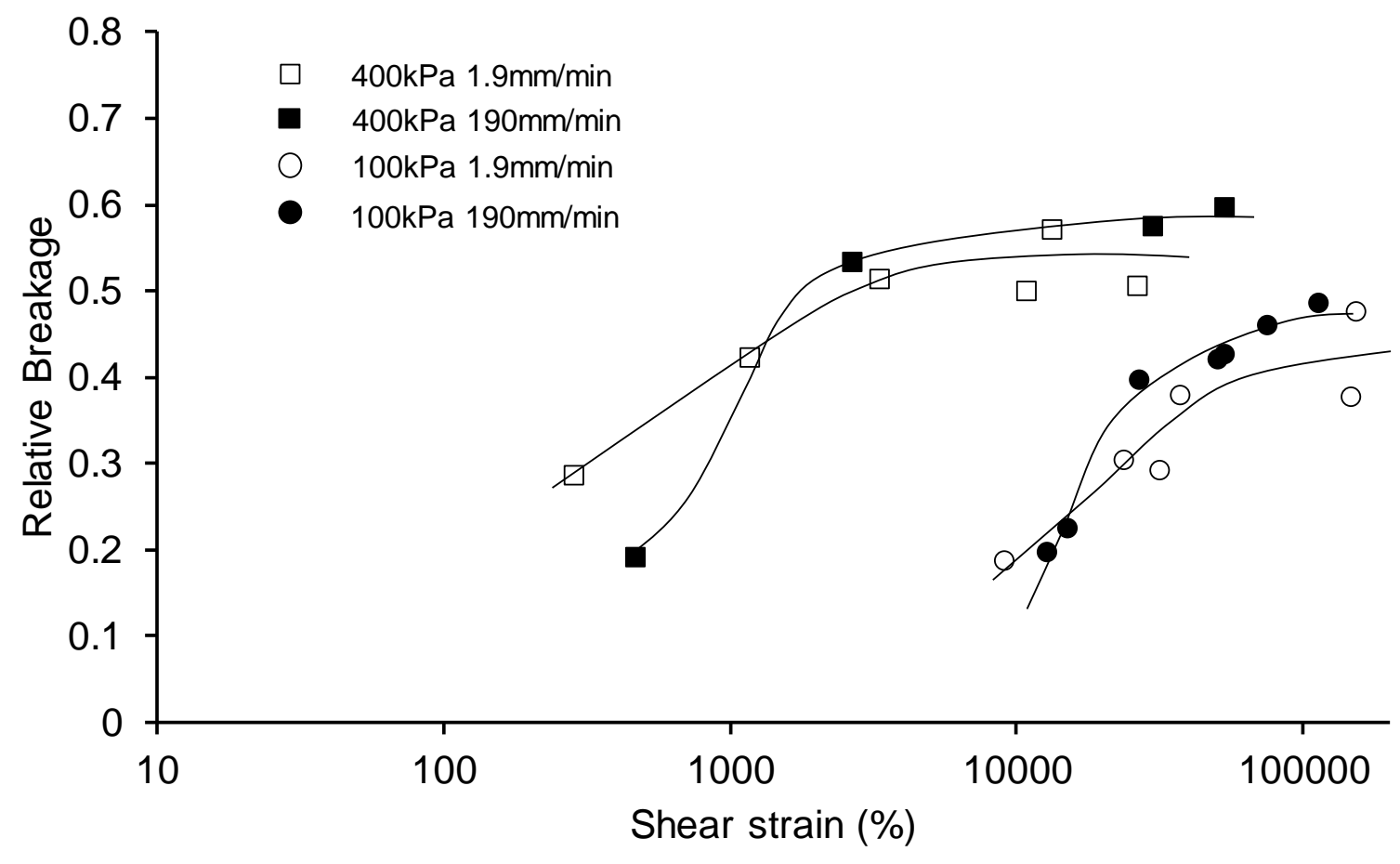

(b)

Fig.4 - The influence of speed of shearing for (a) decomposed granite at 400kPa, (b) Dogs Bay sand (slow tests from Coop et al., 2004) 


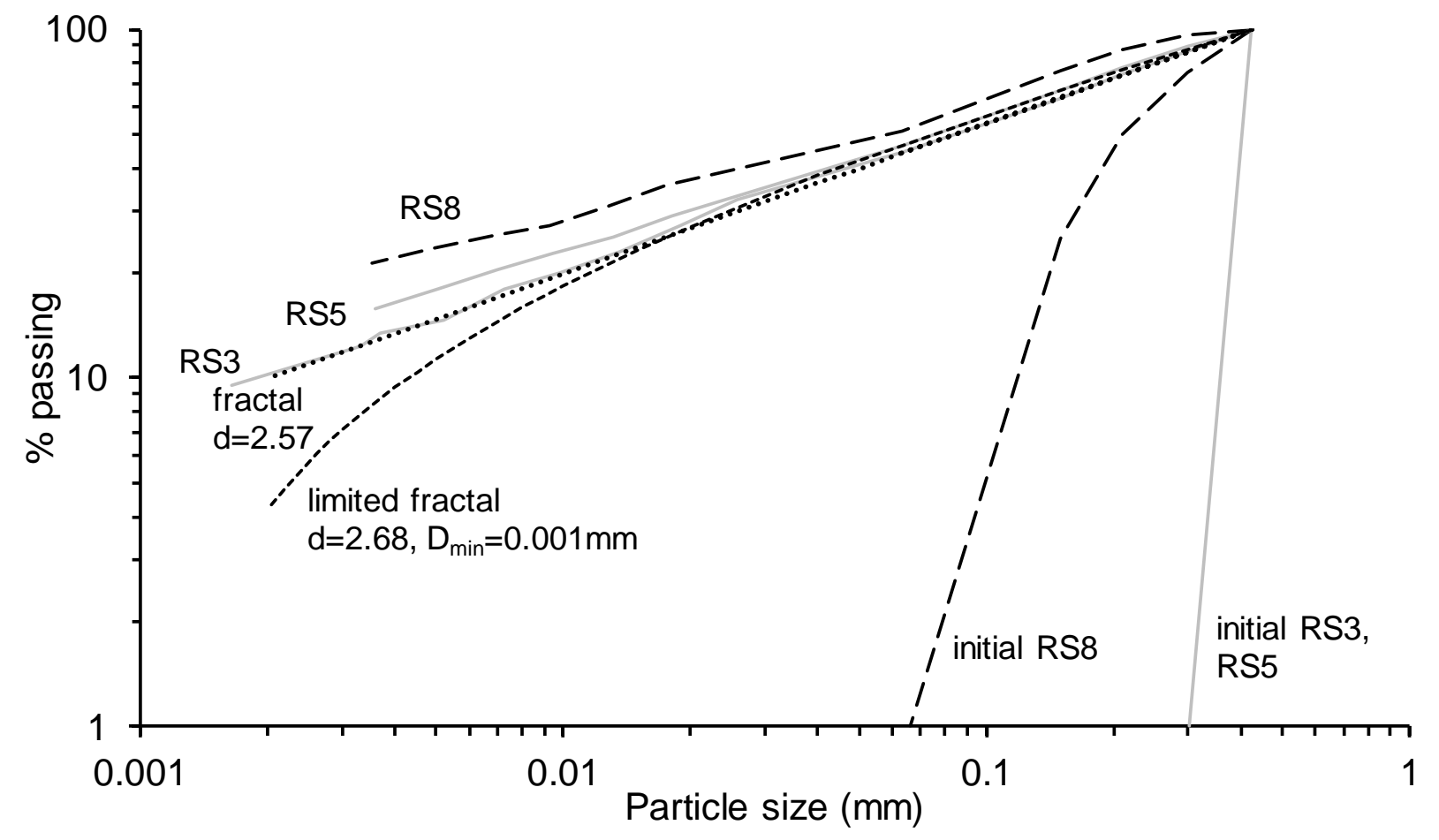

(a)

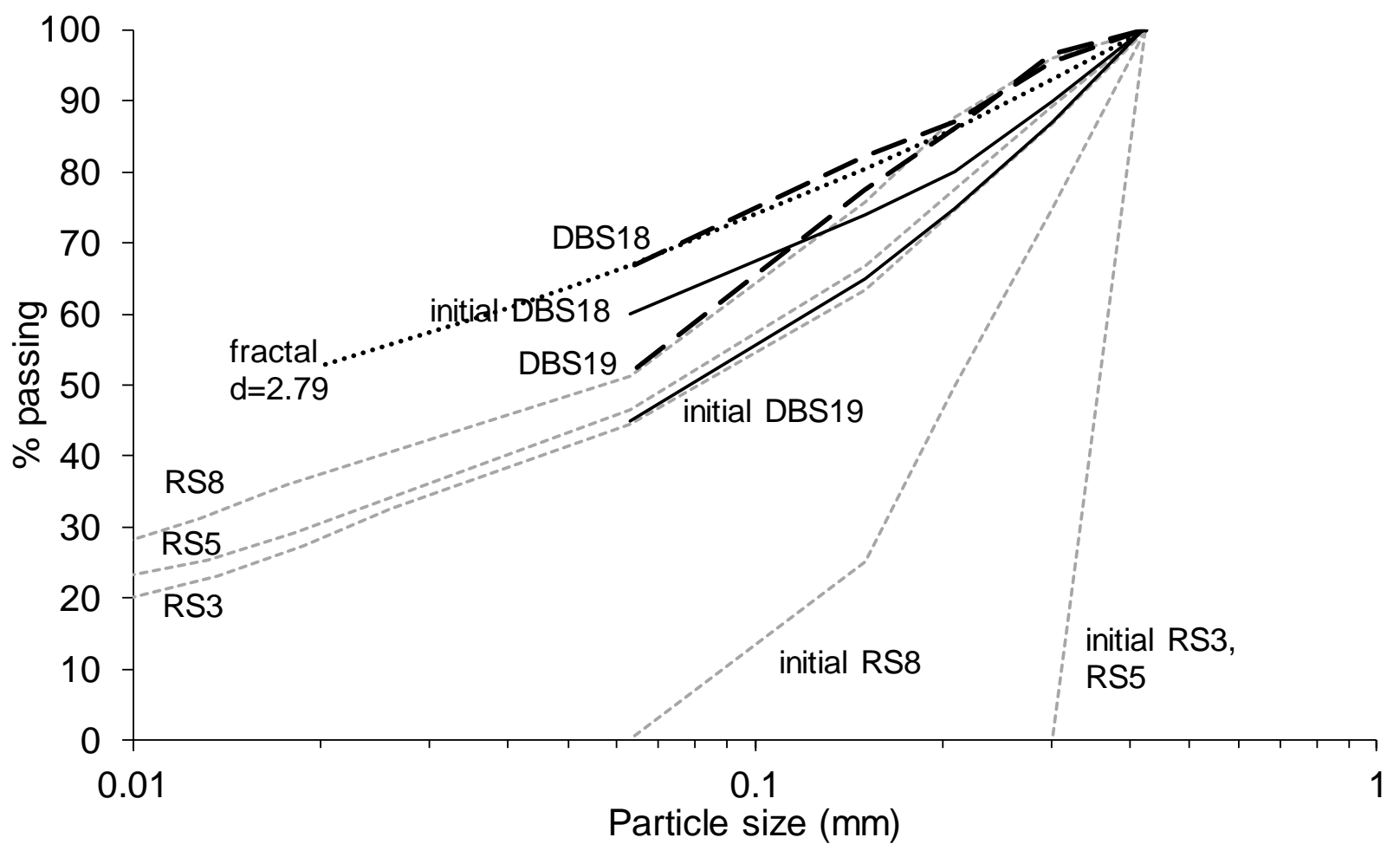

(b)

Fig.5 - Influence of initial grading on final grading for tests with nominal $\sigma^{\prime} v=1 \mathrm{MPa}$ (slow tests only, tests RS3, RS5 and RS8 replotted from Coop et al., 2004). 


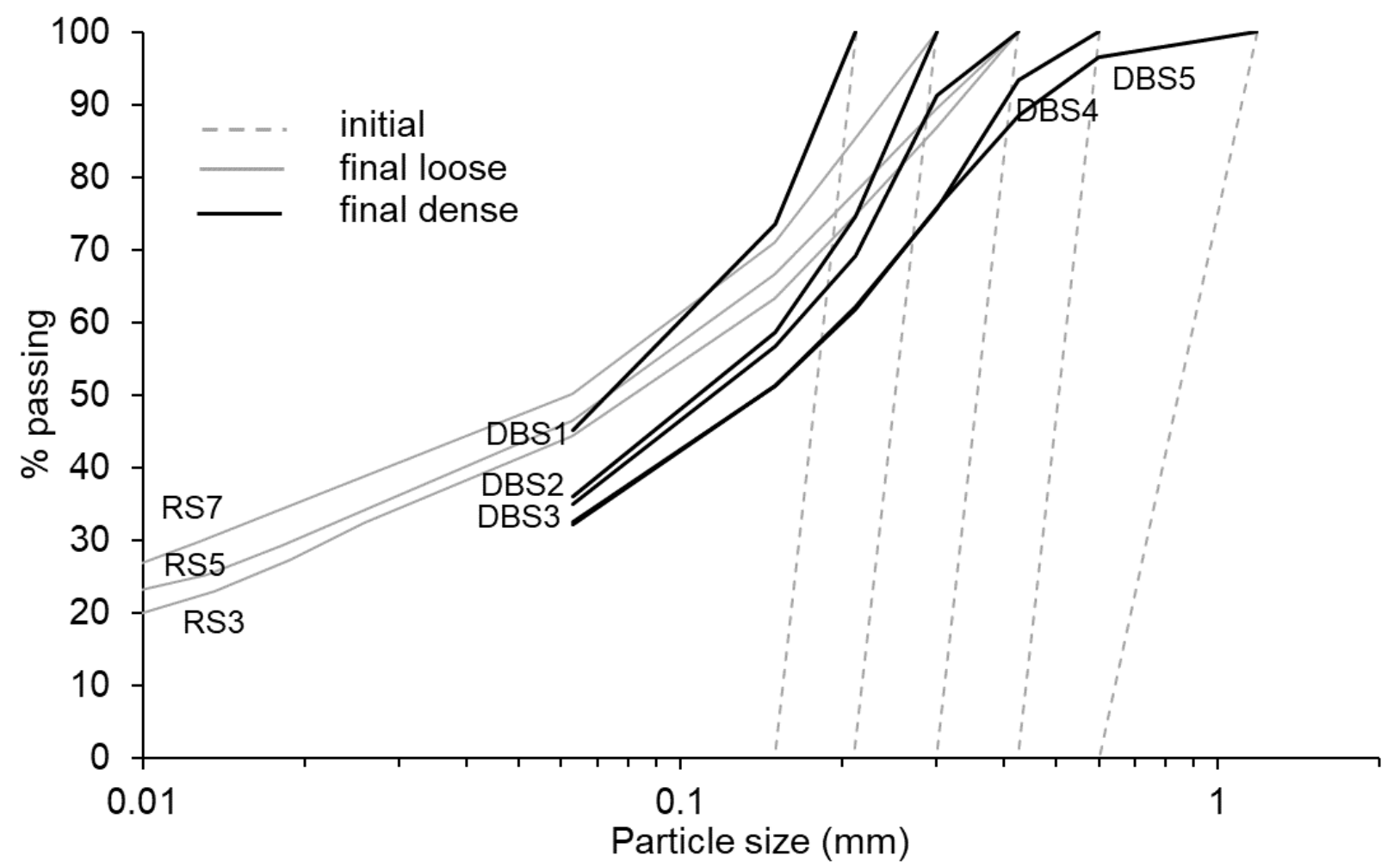

Fig.6 - Influence of absolute particle size on final grading for tests with nominal $\sigma^{\prime} \mathrm{v}=1 \mathrm{MPa}$ (slow tests only, tests RS3, RS5, RS7 and RS8 replotted from Coop et al., 2004). 